Andréa Osório'

'Universidade Federal Fluminense, Niterói, RJ, Brasil

2Universidade Federal do Espírito Santo, Vitória, ES, Brasil

\title{
Ecofeminismo, teorias do care e as críticas a protetoras de animais de rua
}

Resumo: $O$ artigo pretende efetuar uma análise de algumas das críticas recebidas por protetoras de animais de rua, a saber, acusações de irracionalidade, misantropia e sentimentalismo. Essas acusações são lidas à luz do ecofeminismo e das teorias do care, de modo a perceber esse tipo de proteção como uma atividade de care, majoritariamente desenvolvida por mulheres e sujeita a críticas sexistas. O ecofeminismo é mobilizado para combater o sexismo em questão, indicando o potencial que a proteção animal apresenta, de construir outros papéis que não os tradicionais para as mulheres.

Palavras-chave: Protetoras de animais de rua; ecofeminismo; teoria do care; misantropia

\section{Introdução}

Não é fácil, nem simples, ser uma protetora de animais de rua: envolve tempo, dinheiro, espaço, habilidades emocionais e indignação moral. Alimentar, cuidar, resgatar, medicar, abrigar e doar animais recolhidos nas ruas de cidades grandes e pequenas, sobretudo cães e gatos, tem sido uma tarefa caracteristicamente feminina (Andréa OSÓRIO, 2016a; Leandra PINTO, 2016). Não obstante a precariedade e desvalorização desse trabalho (voluntário), as protetoras ainda têm que lidar com críticas caracteristicamente sexistas. Entre elas, pretendo abordar noções de irracionalidade e acusações de misantropia, pensadas a partir de leituras ecofeministas do care. Meu objetivo é demonstrar que uma ética animalitária do care move a proteção animal conforme aqui delineada, e que essa ética, incômoda ao machismo, suscita a elaboração de críticas essencialmente sexistas ao trabalho de proteção animal. Isso não equivale a dizer que as protetoras entrevistadas para esta reflexão adotam, deliberadamente, o feminismo ou se veem como feministas. $O$ que pretendo fazer é uma leitura analítica feminista da proteção animal, a partir de dados

\section{(c) (i)}

Esta obra está sob licença Creative Commons. 
empíricos e teóricos, sem com isso imputar um auto-reconhecimento feminista às interlocutoras.

Uma das inspirações do presente artigo foi a reflexão de Chia-Ju Chang (2012) sobre as gou mama, ou "mães de cachorros" de Taiwan (também encontradas por todo o sudeste asiático). A autora assinala uma crítica feminista da parte dessas protetoras por atuarem na rua, espaço essencialmente masculino na sociedade local, promovendo o bem-estar de animais normalmente vistos como objetos descartáveis, a quem o governo local tenta controlar por meio do extermínio. Nesse sentido, a autora argumenta que sua própria existência tende a ser um reflexo de uma ordem capitalista que os reificou e permitiu um sentido de inutilidade e descartabilidade, e que não o fez apenas contra os animais, mas também reificou seres humanos, transformando-os muitas vezes em mercadorias, em especial as mulheres. Assim, argumenta que a maternagem característica da proteção a animais de rua pode ser desafiadora tanto ao patriarcado quanto ao capitalismo.

Inicio esse artigo com uma apresentação das conexões entre teoria do care e ecofeminismo. Posteriormente, apresento a disputa entre um hiperracionalismo abolicionista e sua visão crítica do care como sentimentalista e irracional, com viés marcante de gênero, não apenas na crítica ao ecofeminismo quanto numa crítica às práticas femininas de protecionismo animal para, então, adentrar especificamente as críticas que as protetoras costumam receber, a saber, de que são misantropas e/ou "loucas". Contra a noção de misantropia, apresento a de misoteria (Jim MASON, 1998), que são práticas e representações perceptíveis de ódio e recusa aos animais, tanto quanto a misoginia, nas críticas que as protetoras recebem. Por fim, politizo o care animalitário da proteção a animais de rua no sentido de apontar quem lucra com a delegação dessa tarefa à parcela feminina da sociedade civil: um estado (patriarcal) omisso, que pouco contribui com políticas de contenção da população de animais de rua.

\section{Care e ecofeminismo}

O ecofeminismo, surgido na década de 1970, é uma vertente das teorias feministas que equaciona modos de dominação da natureza e modos de opressão das mulheres (Karen WARREN, 1996; Lori GRUEN e Linda BIRKE, 1998; Katrina ALBRIGHT, 2002; Greta GAARD, 2011 a) que passou a incorporar também um acento animalitário e uma crítica às teorias utilitaristas (como a de Peter SINGER, 2010) e de direitos dos animais (sobretudo Tom REGAN, 2006) a partir do feminismo (Josephine DONOVAN, 2006). A teoria do care, igualmente feminista, surge na década seguinte a partir da obra seminal de Carol Gilligan (1982), na qual a autora discute formas morais das mulheres, e passa a ser introduzida às questões animalitárias uma década mais tarde (DONOVAN, 2006). O ecofeminismo, por si só, pode não considerar plenamente a questão dos animais e sua conexão, material ou simbólica, com as questões feministas e das mulheres. Minha intenção é tomar a interseção entre ecofeminismo animalitário e teorias do care, para efetuar uma análise das protetoras de animais que pesquisei, indicando como sua experiência e práticas são semelhantes às descritas na literatura consultada.

Foi apenas na década de 1990 que a interseção entre ecofeminismo e movimento animalitário se tornou forte, incluindo o vegetarianismo (Carol J. ADAMS, 2015; ALBRIGHT, 2002), a partir de associações entre a posição das mulheres e dos animais "na ordem patriarcal", um tropo comum nessa literatura. Embora eu utilize o termo ecofeminismo no singular, Warren (1996) sugere que, da mesma forma que existem muitos feminismos, existem ecofeminismos no plural, que seguiriam direcionamentos encontrados no feminismo mais amplo, como vertentes liberais, socialistas, marxistas, radicais e, mais recentemente, queer.

2 Revista Estudos Feministas, Florianópolis, 26(3): e57762 
Não obstante, a autora elege como ponto de confluência a conexão entre dominação da natureza e opressão feminina. Para Gaard (201 1a, p. 198), "um impulso para o início do movimento ecofeminista foi a constatação de que a libertação das mulheres [...] não pode ser plenamente realizada sem a libertação da natureza", e vice-versa. As formas de dominação da natureza se tornam paradigmáticas das formas de dominação entre humanos (racismo, capitalismo, sexismo, heterossexismo, colonialismo, etc.), mas também interespecificamente.

Segundo Gruen e Birke (1998), o ecofeminismo sofre objeções de outras teorias feministas exatamente por mover as mulheres para perto da natureza e dos animais, de modo que isto reduziria ainda mais seu valor no mundo ocidental. Contudo, para as autoras, boa parte da produção ecofeminista deriva de reflexões prévias sobre direitos dos animais que tendem a criticar a separação humano/animal e, pode-se acrescentar, a problematizar a própria separação natureza/cultura, como têm feito, mais recentemente, Donna Haraway (2008) e Bruno Latour (1994), por exemplo. A associação entre mulheres e natureza aponta para uma separação entre a humanidade, sobretudo a sua parte masculina, e a natureza, separação esta que coíbe percepções de que o humano está imerso, faz parte e depende dela (ALBRIGHT, 2002).

Acredito que um ecofeminismo atento aos animais não diminui as mulheres, mas permite que se pense sobre a confluência de variáveis como gênero, humanidade, natureza, cultura, modernidade, ciência e capitalismo, entre outras, em situações complexas. Além disso, como apontam Albright (2002) e Gaard (201 1a, p. 200), a sobreposição de estruturas binárias (feminino/masculino, emoção/razão, humano/animal, entre outras) à oposição cultura/natureza é exatamente o ponto de interesse do ecofeminismo: "todas as categorias de outro compartilham estas qualidades de serem feminizadas, animalizadas e naturalizadas", diz a última autora, se referindo à complexa estrutura pela qual natureza, animalidade e o feminino (ou as mulheres) se tornam associados. Não obstante, parte dessas associações parece essencializar feminino e masculino (ALBRIGHT, 2002) e não leva em consideração formas plurais de feminilidade e masculinidade.

Gaard (201 1b), num balanço que analisa o ecofeminismo e sua transformação sob novas nomenclaturas ${ }^{1}$, indica que sua ascensão nos anos 1980 foi seguida de um declínio nos 1990, até seu eventual apagamento em função, exatamente, das críticas recebidas por seu viés essencialista. Com a autora, contudo, acredito que uma retomada das ideias ecofeministas, sejam sob quais nomenclaturas estiverem dispostas hoje, é interessante para se pensar questões sobre mulheres e meio ambiente, e aqui, especificamente, mulheres e animais. De fato, parte das críticas que contribuíram para o declínio do ecofeminismo nos anos 1990, segundo Gaard (2011b), foi a associação entre mulheres e animais, a qual o ecofeminismo rebateu apontando o antropocentrismo do feminismo em geral ${ }^{2}$.

A ênfase numa separação feminino/masculino parece permear parte da literatura ecofeminista, mesmo quando ela tenta se desvencilhar de identidades de gênero estanques, através da incorporação de teorias queer. Gaard (2011a), por exemplo, afirma que o

\footnotetext{
' Entre outras, a autora elenca o feminismo ecológico, feminismo ambientalista, feminismo crítico ecossocialista e gênero e meio ambiente, elaborados por autoras reconhecidamente ecofeministas.

A nova nomenclatura parece ter sido uma forma de superar a rejeição ao essencialismo ecofeminista.

${ }^{2}$ Adams (2015), uma pioneira na confluência entre mulheres e animais no ecofeminismo, identifica formas de exploração de animais fêmeas, como a indústria leiteira e de ovos, às quais se pode acrescentar toda forma de matrizes reprodutoras de cães e gatos de raça, além de outros animais domesticados. A inclusão dos animais nas reflexões e preocupações feministas em geral poderia ser útil pela revelação de formas de exploração do corpo feminino ou feminizado, o que de certo inclui identidades transgêneras tanto quanto associações simbólicas entre o feminino e outros corpos.
} 
ecofeminismo rejeita o dualismo, mas reiteradamente se refere à racionalidade como masculina. Quero alertar o(a) leitor(a) de que a sensação de identidades femininas estanques e essencializadas perpassa parte da produção ecofeminista e tem sido revista com maior ou menor sucesso. Tal sensação não configura, contudo, o objetivo do ecofeminismo, nem o meu. Ela deriva das associações simbólicas binárias que o ecofeminismo tenta desconstruir. A própria associação do care com trabalhos normalmente desempenhados por mulheres pode acirrar essa sensação. Adams, a esse respeito, assinala que

Eu não proponho uma visão essencialista das mulheres, tampouco. Eu não acredito que as mulheres são inatamente mais cuidadosas [caring] do que os homens, ou que tenham uma qualidade pacifista essencial. [...] eu não acredito que as mulheres essencialmente 'cuidam' [care, no original entre aspas], mas eu acredito que é essencial para todos nós cuidar e reconhecer relacionamentos (ADAMS, 2015, p. 22, grifo original).

O essencialismo é um problema, igualmente, para as teorias do care. Gilligan (1982) foi criticada por isso, sobretudo na ausência de considerações sobre classe, raça e situações sócio-históricas nas quais o care se desenvolve (Natacha BORGEAUD-GARCIANDÍA, 2009), especialmente quando se observa que trabalhos de cuidado recaem frequentemente sobre mulheres de camadas populares, de grupos étnicos minoritários, desvalorizados e/ou imigrantes (Pascale MOLINIER, 2012). Nesse sentido, nem todas as mulheres "cuidam" e o care não deveria ser uma ética essencializada, mas analiticamente observada como genderizada e interseccionalizada (MOLINIER, 2014). Porém, Molinier (2014, p.19) indica como foi criticada justamente por ter publicizado os pertencimentos étnico-raciais de mulheres em trabalhos de care, o que chegou a ser considerado por uma interlocutora sua como "perpetuar a visão de que as mulheres negras são sujeitadas aos trabalhos sujos de cuidado".

\section{Care versus utilitarismo}

Donovan (1996; 2006) indica que uma teoria feminista e animalitária do care foi desenvolvida como uma reação às teorias utilitaristas e de direitos dos animais, normalmente subsumidas às reflexões seminais de Peter Singer (2010) e Tom Regan (1986; 2006). A crítica feminista aponta limitações epistemológicas em tais abordagens por seu enfoque estritamente racionalista, iluminista e permeado por uma teoria liberal dos direitos que ignora as assimetrias de poder estruturantes da sociedade contemporânea. Além disso, dispensam a compaixão, a empatia e a piedade como irrelevantes, conforme identifico mais abaixo. Ao contrário, a abordagem feminista tomaria tais emoções como respostas ao debate filosófico e como modos autênticos de conhecimento.

O problema parece mais denso do que posso tratar aqui, mas é interessante observar que a tensão não é superficial e levou o próprio Regan a responder que "a ética do cuidado feminista renuncia ao uso da razão" (REGAN, 1991, p. 142, apud DONOVAN, 1996). Em resposta, Donovan (1996) enumera filósofos que tomam a compaixão como um elemento racional e cognitivo (e, certamente, não como uma exclusividade feminina).

De fato, a oposição entre bem-estaristas e abolicionistas não chega a definir a proteção a animais de rua. O que me incomoda nessa classificação é que ela subsume os pontos de vista de Singer (2010) e Regan (1986; 2006), que não incluem o elemento discursivamente mais visível entre protetoras que analisei, que é, justamente, a preeminência da moral e das emoções - na forma do cuidado e do amor pelos animais - nas justificativas de seu engajamento. A proposta ecofeminista de um care animalitário parece mais afinada ao que percebi em campo. 
O care pode tomar um importante papel no ecofeminismo. Deane Curtin (1991), por exemplo, tenta desenhar uma ética ambientalista ecofeminista a partir de uma comparação entre o discurso dos direitos, comum em ativistas de direitos dos animais, e o discurso do care. Donovan (1996) argumenta que o próprio discurso de direitos foi constituído para um sentido masculino de propriedade e espaço público, quando às mulheres cabia (e ainda cabe) o necessário trabalho de cuidado doméstico. Essa configuração social genderizada teria constituído "uma diferente tradição ética" entre as mulheres, que a autora relaciona à ética do care, uma lógica amplamente presente na esfera doméstica e feminina. Albright (2002) identifica na ética do care o reconhecimento do direito inerente dos animais a segurança e integridade corporais, baseado não em racionalidade, mas em suas vidas emocionais e suas relações com humanos, que teriam uma responsabilidade ética de agir contra o seu sofrimento.

Para Curtin (1991), se a ética não for mais uma questão relacionada aos direitos (dos animais, das mulheres, etc.), ela pode ser pensada como uma prática que dá lugar central ao care e a valores relacionados a ele, como o amor e a confiança. A ética do care seria melhor para expressar a conexão entre razão e emoção. Analisei o discurso emocional das protetoras brasileiras em outro lugar (OSÓRIO, 2016b), mas é conveniente aqui retomar a percepção de que as principais motivações para se tornar uma protetora, do ponto de vista das entrevistadas, é o amor pelos animais e um senso de obrigação humana de ajuda-los, de tal modo que a separação entre emoção e moral só pode se dar num plano analítico. Assim, quero já apontar que se trata de uma ética do care o que move essas pessoas. Como aponta Borgeaud-Garciandía,

[...] la 'solicitud' (la sollicitude), la 'atención' (l'attention), la 'compasión' (la compassion), la 'preocupación' (le souci) o el 'cuidado' (le soin, entendido en relación directa con la salud) son algunas de las expressiones que, cuando no retoma diretamente lampalabra inglesa, sirven alternativamente para expresar la idea del care y evocan sus diversas dimensiones aí como las del trabajo de cuidador (BORGEAUD-GARCIANDÍA, 2009, p. 139, grifo original).

\section{Cuidar dos animais}

Parte do que enseja a utilização de teorias do care no presente artigo é a percepção das próprias entrevistadas de que sua atenção aos animais abandonados é uma forma de cuidado, conforme excertos abaixo. Ela é mais claramente pensada como uma atividade que subsume outras, como o tratamento veterinário, a alimentação, a higiene, o resgate e o bem-estar geral do animal de rua.

Então, o protetor de animais, ele faz isso: ele retira o animal de uma situação de abandono, de risco, de doença, de fome, de tudo, pra poder culdar daquele animal e colocar ele em condição de ser adotado, tá? [...] Então, eu acho que basicamente protetor faz isso: ele resgata, ele tenta dar uma vida, mudar o destino do animal, entendeu? Então através disso: através do resgate, dos cuidados e depois, adoção. Sempre visando isso: botar o animal inteiro para que ele possa ter uma chance de ser adotado (Damiana ${ }^{3}, 50$ anos).

Eu acho que a proteção dos animais, assim, é a gente resgatar animais, né, de situação de risco extremo, cuidar desses animais, esterilizar esses animais e, depois, quando eles já estiverem aptos, trazer pra feira [de adoção] pra conseguir boas doações responsáveis (Ângela, 31 anos).

${ }^{3}$ Todos os nomes são fictícios. Um perfil socioeconômico das entrevistadas foi publicado anteriormente (Osório, 2016c). 
É muito desgastante. Dá muito trabalho, dá muita despesa pra gente que é sozinho, né? Eu faço tudo sozinha, eu não sou de grupo nenhum. Mas também é muito gratificante, porque você resgata um animal na rua, maltratado, doente, com fome, você culda, trata, bota ele todo bonitinho e consegue um lar pra ele. Então, você faz a diferença na vida dele, entendeu? Morar na rua e viver só três anos, que é a média que eles vivem, ou conseguir um lar amoroso, seguro e viver quinze anos, entendeu? (Berenice, 43 anos).

Algumas entrevistadas alertam que, aos animais abandonados, falta, justamente, 0 cuidado, antítese do abandono.

A maioria é mais doença. Doença pela rua mesmo. Assim, falta de cuidado. Às vezes, não é nem uma doença especifica, mas tá debilitado porque tá cheio de verme, porque machucou, tipo, ou foi atropelado, né? Doença, doença mesmo, a gente até resgata, até encontra, mas na maioria dos casos que eu pego eles estão mais debilitados mesmo até pela carência na rua, né? De não ter um cuidado, de não se alimentar adequadamente e tudo (Cássia, 33 anos).

São pessoas que literalmente jogam fora, por não querer cuidar mesmo. Não querem cuidar, não querem. Principalmente não querem gastar dinheiro com animal. Assim eles param na rua (Cecília, 51 anos).

O cuidado é uma atenção às necessidades animais que são marcadas tanto por dispositivos sociotécnicos (LATOUR, 2001), como a medicina veterinária, quanto pela convivência e a compreensão de sua individualidade. $O$ animal precisa de abrigo, comida e medicação, mas precisa também de amor, de afago, de afeto, de família, de casa. $O$ cuidado é, simultaneamente, material, moral e afetivo.

Sigo, aqui, o apelo sociológico de Molinier (2014) para se ouça o que dizem as cuidadoras: as protetoras entrevistadas não associam seu trabalho de cuidado a uma identidade de gênero ou uma essência feminina. Para elas, como acredito que os excertos deixem claro, cuidar dos animais é uma obrigação humana, sem marcação de gênero. Sem operar numa dicotomia masculino/feminino, elas introduzem dicotomias entre o humano e o animal. Embora não coloquem a proteção como uma tarefa de mulheres, as reflexões sobre o care, que busquei incorporar no presente trabalho, permitem perceber, justamente, que esta proteção tem impacto sobre as mulheres, não apenas sobre os animais.

Não necessariamente quantificável nem redutível aos custos envolvidos, parte do trabalho das protetoras diz respeito às emoções ${ }^{4}$, ao cuidado, à maternagem. $\mathrm{O}$ fator emocional é tão presente nesse universo que ele tem chamado a atenção de pesquisadores (Érica PASTORI e Liziane MATOS, 2015; OSÓRIO, 2016b; Leandra PINTO, 2016). Cuidar dos animais é, em suma, amá-los. Aqui, como entre os cuidadores de idosos que Molinier analisa, o amor é uma razão para cuidar, embora ambos os termos tenham sentidos múltiplos:

O significado da palavra amor não é o mesmo para as cuidadoras e para o quadro dirigente. Para elas essa palavra designa aquilo que viabiliza o trabalho, que o torna possível. Quando Ihes perguntei o que significa 'trabalhar bem', as cuidadoras me responderam: 'é trabalhar com seu coração' (MOLINIER, 2014, p. 28).

Essa percepção emocional é muito comum na proteção a animais de rua e emergiu quando as entrevistadas foram perguntadas sobre sua definição de proteção. Dentre as respostas, destaco um eixo emocional formado pelas noções de amor, sofrimento, sensibilidade, respeito e coração, e um eixo moral formado pelas noções de missão,

${ }^{4} \mathrm{O}$ desgaste emocional de ativistas animalitárias foi analisado por alguns autores. Gaarder (2008) indica que as ativistas descrevem seu trabalho como "altamente emocional" e exaustivo. Adams (2015) também menciona desgaste emocional em sua trajetória de militância feminista.

6 Revista Estudos Feministas, Florianópolis, 26(3): e57762 
obrigação, dignidade, proteção, ajuda, salvamento, solidariedade e educação. Entre esses eixos, percebe-se que são destacadas atividades (resgatar, cuidar, proteger, doar, trabalhar, educar, ter uma missão) e sensibilidades (amor, respeito, gratificação, solidariedade, dom).

Tais definições afastam, junto a outros fatores, sua percepção de que a proteção seria uma profissão ${ }^{5}$. Em primeiro lugar, a recusa a essa categoria advém da recusa à remuneração, conforme excertos a seguir. Em segundo lugar, gostaria de sugerir, por ora, que tal recusa se relaciona com essa percepção do care como uma atividade emocional e moral.

Não é profissão. Tá entre o hobby também. Você tem que gostar, né. Uma coisa que você faz por amor (Amanda, 22 anos).

Na verdade, as pessoas confundem proteção com profissão e proteção não é profissão. Ninguém tá ali pra ganhar dinheiro com aquilo (Dora, 40 anos).

Profissão é quando a gente ganha dinheiro. A gente não ganha dinheiro, a gente dá é nosso amor (D. Adriana, 71 anos).

Aqui, recorro mais uma vez a Molinier, a despeito de sua análise enfocar o âmbito do trabalho de care remunerado, quando ela sugere que

[...] ○ paradigma da profissão não é o melhor para atingir o respeito ao trabalho do cuidado, nem para compreender seu ethos. [...] As relações humanas são governadas por afinidades, os indivíduos não são intercambiáveis. Ser 'profissional' significaria ocuparse de todo mundo da mesma maneira, com empatia e distância, o que estipula uma regra impossível de ser cumprida (MOLINIER, 2014, p. 28)

A recusa à remuneração incorpora, entre outros fatores, essa impossibilidade de profissionalizar as relações de afinidade, mesmo que no caso pesquisado elas digam respeito a relações interespecíficas e não entre humanos. Molinier (2014, p. 29) alerta, contudo, que as cuidadoras remuneradas não descartam a noção de serem profissionais no sentido de "que a questão é mais a de saber como se ocupar de todo mundo quando é impossível amar a todos da mesma maneira".

O cuidado, remunerado ou não, não escapa a algum tipo de efeito emocional e o discurso emocional das protetoras elabora, consistente e repetidamente, esse efeito sobre elas, mas também o efeito de suas emoções (de sua compaixão e amor) sobre os animais que elas ajudam. Nesse discurso, é o amor que salva vidas, mesmo que ele seja permeado por conhecimentos tecnocientíficos (OSÓRIO, 2016c). É o conjunto de conhecimentos e dispositivos que elas acionam, cognitivos, emocionais e corporais, que essa noção de amor subsume.

Para Donovan (2006), a teoria do care tem uma natureza dialógica: não se trata de cuidar dos animais como mães cuidam de seus filhos, mas de ouvir os animais, dar-lhes uma atenção emocional, levando a sério o que podem nos dizer. A sua fala é expressa, segundo ela, geralmente em bases corporais, de modo que nenhum conhecimento especializado sobre esta ou aquela espécie é necessário. Mas é verdade também que essas leituras podem levar a compreensões equivocadas, sobretudo antropomorfizando as condutas animais. Eliane Rapchan e Walter Neves (2005) discorrem, por exemplo, sobre o problema da compreensão das condutas animais pelos seus tratadores em situações de cativeiro, indicando o antropomorfismo como um dilema e não uma solução. Donovan (1996), contudo, contesta o processo como antropomórfico, frisando a ideia de que a

\footnotetext{
${ }^{5}$ Para uma discussão sobre a antiprofissionalização na proteção a animais de rua, ver Osório (2017).
} 
observação e a atenção seriam suficientes para a compreensão do mundo habitado pelo Outro animal. O sentido da proposta é, segundo a própria autora, colocar os animais de carne e osso nas análises, e não apenas teoriza-los. O seu estatuto moral estaria relacionado com a nossa percepção de que eles têm sentimentos, não apenas interesses ou direitos, numa homologia entre sentimentos animais e humanos que tornaria imoral o seu sofrimento.

Acredito que a teoria do care não é sobre generalizações, e sim sobre relações interespecíficas singulares. A questão, para mim, não é a de apreender fenomenologicamente as mentes animais, mas de compreender o que animais individuais comunicam em situações interespecíficas particulares e acionar, nessas situações, uma conduta de acordo com a ética do cuidado. A despeito de Donovan (1996) retomar a fenomenologia de Max Scheler (1970) para indicar que o autor incluía animais em sua proposta de método, a qual continha uma "gramática da expressão" corporal pensada como universal, e que permitiria a compreensão interespecífica, a abordagem fenomenológica não encerra os problemas relacionados às mentes animais. Em outras palavras, a comunicação pode se dar independentemente de uma compreensão do funcionamento mental animal.

De um modo geral, todo o problema parece se assentar na "grande divisão" (LATOUR, 1994), pela qual animais e humanos seriam tão distintos que não poderiam nem se compreender, nem se comunicar. É interessante assinalar, nesse sentido, que na maioria das leituras efetuadas para o presente artigo, a comunicação e a compreensão são sempre pensados, ou descritos, como dos humanos para com os animais, e não vice-versa, numa assimetria de cuidados na qual os humanos estão em posição privilegiada de cuidar, mas não de serem cuidados pelos animais.

A biologia e suas ramificações internas são fundamentais na construção das percepções de quem sofre, como sofre e se os animais têm emoções e moral. Minha objeção a esse tipo de argumento, característico do abolicionismo animal não feminista, é de que ele engendra a biologia como uma verdade sobre o mundo e não uma leitura sobre os fatos que, seguindo Latour (1994; 2001), não deixam de existir por si mesmos. Desse modo, a questão não é tanto acessar esses fatos cientificamente, mas reconhecê-los, independente de validações científicas. Ainda com Latour (1994; 2001), receio que tal preeminência recaia na "grande divisão" entre natureza e cultura, pela qual apenas algumas ciências, mas necessariamente ciências, são capazes de apreender uma natureza apartada da cultura.

No caso das protetoras que analiso aqui, percebi uma mobilização tanto de conhecimentos tecnocientíficos, através de médicos veterinários, quanto de percepções oriundas do convívio com animais particulares e espécies privilegiadas como animais de estimação. De fato, uma das protetoras entrevistadas era veterinária e outras três estudavam veterinária no momento das entrevistas. Parte dessas protetoras foi recrutada nos cursos de medicina veterinária e parte decidiu dedicar-se à formação porque eram protetoras, demonstrando as intrincadas formas pelas quais ambas as atividades dialogam nas práticas de proteção a animais de rua. Da veterinária vêm uma série de conhecimentos acionados pelas protetoras para reconhecer doenças e condutas animais, mas parte do conhecimento sobre essas condutas, que não é oriundo da etologia, advém da convivência que lança um olhar atento. Esse olhar é o que Donovan (2006) caracteriza como parte da ética do care.

\section{Gênero, geração e sentimentalismo}

Há uma leitura da proteção a animais que ridiculariza e inferioriza protetoras por serem mulheres e idosas, classificando-as de femmes à chats (Yves DELAPORTE, 1988), lady of the cats, velhas com gatos e similares. Nesse contexto, é o próprio sentimento pelos 
animais, associado às mulheres, como todo sentimentalismo, que é ridicularizado e, como bem aponta Emily Gaarder (2011), pode se tornar um problema para o movimento animalitário. Nos Estados Unidos, "as ativistas dos direitos dos animais são frequentemente acusadas por seus oponentes de serem abertamente emocionais e anti-intelectuais" (GAARDER, 2011, p. 59).

Tom Regan, por exemplo, enfatiza que

[...] o que está errado [na forma como tratamos os animais] não é a dor, não é o sofrimento, não é a privação. Estes compõem o que está errado. Muitas vezes - quase sempre - eles o fazem pior, muito pior. Mas eles não são o erro fundamental. $\bigcirc$ erro fundamental é o sistema que nos permite ver animais como nossos recursos, aqui [disponíveis] para nós [...] (REGAN, 1986, p. 179).

As emoções (animais) se tornaram um epifenômeno. Elas não são o cerne da preocupação do autor, mas uma consequência do sistema. Assim, preocupar-se com essas emoções não leva ao seu âmago: o "erro fundamental" não está em provocar dor e sofrimento, mas em pensar e tomar os animais como recursos, do que o sofrimento é apenas um efeito. Sentiment(alism)os não tem vez aqui. Em Regan, um abolicionista animal, talvez a questão do sentimento seja até mais fortemente rechaçada do que em outros autores ${ }^{6}$, na medida em que ele o conecta a atitudes bem-estaristas que minimizariam exatamente 0 sofrimento animal, porém permitindo a manutenção de sua exploração.

Regan (1986, p.180) faz, então, uma defesa da filosofia e de sua posição ética justamente a partir de uma antítese entre emoção e razão: "eu acredito que a ideia de direitos dos animais tem razão [lógica], não apenas emoção, em seu lado". Mas, como seria imoral não ser afetado pelo sofrimento animal, o autor assinala que "meus sentimentos sobre como os animais são às vezes tratados corre tão profunda e fortemente quanto o dos meus compatriotas mais voláteis" (REGAN, 1986, p.180), depois de se referir a seus argumentos como "cerebrais". Trata-se de uma questão racional, não emocional: para ele, ser gentil e contra a crueldade é bom, mas não sustenta uma teoria moral da ação. A tensão entre razão e emoção continua, como quando o autor supõe que espécies carismáticas tenderiam a ser beneficiadas em termos de proteção por conta das emoções que suscitam nas pessoas, enquanto outras viveriam num ostracismo protetivo por não serem tão amadas.

Haraway (2008), sobre a reflexão de Gilles Deleuze e Felix Guattari (1997) em Mil Platôs, comenta nunca ter visto um caso tão claro de misoginia, medo de envelhecimento, falta de curiosidade pelos animais e horror à ordinariedade da carne quanto o expresso na passagem em que eles criticam animais de estimação individualizados, amados pelos seus donos, especialmente mulheres idosas:

Pequenos cães caseiros e as pessoas que os amam são a última figura de abjeção para D\&G [Deleuze \& Guattari], especialmente se essas pessoas forem mulheres idosas, o próprio tipo de sentimental. [...] A velha, mulher, pequena, amante de cães e gatos: esses são quem e o que deve ser vomitado para fora por aqueles que se-tornarãoanimais (HARAWAY, 2008, p. 30).

Essa associação entre mulheres, envelhecimento e amor pelos animais não é nova. Coral Lansbury (1985), historiadora que analisa elementos da relação entre mulheres e

\footnotetext{
${ }^{6}$ Regan (1986) chega a equivaler o interesse no utilitarismo a um problema de sentimentos e desejos para rechaçar essa abordagem em prol de sua própria, baseada em valores inerentes e seus consequentes direitos individuais. Para o autor, é a razão, e não o sentimento, que força o reconhecimento do valor inerente dos animais. Sua posição é sempre contrastada ao utilitarismo de Peter Singer (2010), que coloca ênfase no sofrimento a partir da noção de senciência, embora igualmente rechace processos emocionais e de compaixão.
} 
proteção animal na Inglaterra eduardiana, especialmente a vivissecção, aponta que o fisiologista francês Élie de Cyon descreveu as antivivisseccionistas como mulheres idosas:

[...] deixe meus adversários me contradizerem, se eles puderem mostrar, entre as líderes da agitação, uma garota jovem, rica, bonita e amada, ou alguma jovem esposa que tenha encontrado em seu lar a plena satisfação de suas afeições (LANSBURY, 1985, p. 83).

Em outras palavras, uma vida marital, de preferência com filhos, erradicaria qualquer inclinação à reforma social por parte das mulheres, especialmente se elas estivessem no mercado matrimonial, demonstrando as representações presentes no tratamento dado às mulheres no âmbito das críticas à sua participação na proteção animal. Ocorre que alguns expoentes do antivivisseccionismo eram jovens ricas, notadamente Louise Lind-af-Hageby que, com Leisa Schartau, publicou The Shambles of Science, descrição antivivisseccionista das aulas de fisiologia na London School of Medicine efetuada por elas como alunas de lá (LANSBURY, 1985).

O gênero e a idade parecem, portanto, marcadores da proteção animal associada a um tipo de sentimentalismo, afeto ou compaixão. Não creio que seja coincidência que o prefácio à edição de 1975 de Libertação Animal, de Peter Singer (2010), traga uma separação explícita entre amor aos animais, representado por duas senhoras que o convidam para o chá, e seus questionamentos morais filosóficos no quais, segundo ele, gostar ou não de animais não tem relevância. A anfitriã de Singer (2010) queria apresenta-lo a uma amiga que era diretora de um hospital para animais de estimação doentes, mas, ao invés de se interessar pelos animais doentes, ele apenas observou que elas comiam presunto. Esse episódio paradigmático é retomado por Donovan (2007) para indicar, justamente, a feminização do sentimentalismo animalitário por Singer (2010).

A tensão expressa nessa situação exemplar representa uma separação entre universos pretensamente feminino e masculino, público e privado, mas também as diferentes formas de se pretender defender e proteger animais desde o século XIX. Formar novas ideologias, controlar as classes trabalhadoras e sua lida com os animais, criticar o uso de animais na moda feminina (raramente na masculina) ${ }^{7}$, tentar controlar a ciência e instituir uma ética médica, professar o vegetarianismo, acolher animais doentes e de rua, todas essas questões emergem no século XIX como parte de um macromovimento animalitário e continuam disputando seguidores até o momento. No entanto, umas são mais valorizadas do que outras.

Como nas comuns armadilhas sexistas, onde o que é feminino é sempre desvalorizado, os animais se tornam mais desvalorizados quando são assunto de mulheres e, vice-versa, as mulheres se tornam menos valorizadas quando se interessam por animais de uma forma não econômica, (supostamente) não filosófica ou não científica. $O$ sentimentalismo pretensamente feminino dá o verniz final a uma relação emocional com animais de estimação que é criticada por (de novo, supostamente) não empreender nenhuma tarefa intelectual. Em Singer (2010), os animais de estimação não têm muito espaço, optando-se pelo foco em animais economicamente relevantes e animais de laboratório, que ensejam uma indústria à parte. $O$ afeto pelos animais de estimação parece afastar tais animais das reflexões do autor e o mesmo ocorre com Regan (1986; 2006).

Donovan (2007) chama a atenção para a ironia dessa ênfase na racionalidade, identificando sua origem no objetivismo cartesiano que, justamente, costuma ser apontado

\footnotetext{
${ }^{7}$ Ver Hilda Kean (1998) e Gaarder (2011). No século XIX, a grande questão eram as plumas dos chapéus femininos. No século XX, o dilema foi transposto para os casacos de pele. Pouca atenção é dada aos calçados e outros itens de couro que atingem o vestuário de ambos os sexos. Sobre o sexismo nesse tipo de campanha, entre outros problemas, ver as acusações que o ecofeminismo dirigiu ao PETA (Albright, 2002).
} 
como peça fundamental na atual forma capitalista de dominação dos animais, estabelecendo a metáfora mecanicista. De fato, grande parte da literatura ecofeminista consultada identifica em Singer (2010) e Regan (1986) uma ênfase na ética e na racionalidade e uma subvalorização de aspectos emocionais e de care que parte do ecofeminismo toma como modelo paradigmático das relações que deveríamos empreender tanto intra quanto interespecificamente. Donovan (2007) associa esse paradigma a teóricas mulheres ${ }^{8}$, instituindo gênero como uma variável importante não apenas na análise da realidade, mas na análise crítica das teorias animalitárias.

Adams (2015), por sua vez, indica que o próprio vegetarianismo foi acusado de ser sentimental e feminino. Porém, a autora toma o ataque como uma tentativa de esvaziamento da crítica vegetariana. Similarmente, pode-se compreender o hiperracionalismo dos direitos dos animais ou as acusações de sentimentalismo dirigidas às militantes animalitárias como um esvaziamento da crítica (eco)feminista, na medida em que mantém representações estereotipadas e assimetrias de gênero.

\section{Irracionalidade}

Tentei indicar acima as confluências entre a preeminência de um discurso emocional e moral entre protetoras de animais de rua e o paradigma da ética do care, incluindo as críticas ecofeministas ao (hiper)racionalismo do abolicionismo animal. Agora, gostaria de apresentar como essa ênfase nas emoções e no cuidado com animais, que são vistos como objetos descartáveis, leva as protetoras a se sentirem - e serem acusadas de irracionais, com uma forte ênfase na noção de loucura.

Entre as protetoras entrevistadas, algumas reportam terem sido consideradas "loucas" ou "malucas", ou referem-se a si mesmas desta forma, por resgatarem animais de rua, conforme excertos abaixo.

Porque, na verdade, por mais que seja trabalhoso, por mais que você gaste dinheiro, é muito prazeroso. É uma coisa que faz a gente se sentir muito bem. As pessoas talvez não entendam isso. Têm algumas pessoas que acham: 'nossa, que mulher maluca!', entendeu? Mas não é isso (Damiana, 50 anos).

Se tivesse em todos os municípios a questão da castração, não existiria tanto animal abandonado e não ia ter tanta gente, né, ocupando o tempo cuidando dos animais, porque [pensam] 'ah, o protetor é louco'. Não, o protetor não é louco, né? Enquanto muitos se preocupam com cabelo, com carro, a gente se preocupa com os animais. É um amor (Daniela, 42 anos).

Eu nem conhecia as pessoas que faziam a mesma coisa que eu. Até onde eu... eu acreditava que eu era a única louca, assim, que tinha vontade de fazer essas coisas e que todo mundo me dava esporro, entendeu? Aí pouco antes de eu casar [foi] que eu entrei no Facebook, que eu comecei a ter contato com as outras pessoas também (Cássia, 33 anos).

Pinto (2016) identifica a insanidade como parte de argumentos críticos à proteção animal. Ao analisar a legitimidade das protetoras em interseção às questões de gênero, a autora indica que elas

[...] são consideradas por muitos como mulheres problemáticas que, ao invés de investir em relações com outras pessoas, gastam todo o seu tempo e dinheiro no cuidado com os animais. Por esse motivo, são muitos os relatos de mensagens recebidas pelas protetoras

${ }^{8} \mathrm{O}$ que definitivamente não significa que seja um ponto de vista compartilhado por todas as mulheres, senão recairíamos no determinismo biológico do qual o feminismo tenta se afastar. 
carregadas de estereótipos e preconceitos por dedicarem suas vidas à causa animal. Assim, a proteção aos animais é considerada sob a ótica de uma fuga da realidade, e por esse motivo muitas vezes não é vista como uma ação social, mas como efeito de distúrbios que atingem essas mulheres (PINTO, 2016, p.139-140).

Uma queixa ouvida também por Pedro Santos (2014, p. 180) em um debate na Câmara Municipal do Rio de Janeiro, no qual uma protetora relatou as dificuldades enfrentadas por protetores de animais de rua, acrescentando: "temos problemas até com nossos maridos, com nossas famílias, que dizem que nós somos loucos". "Proteloucas" (PINTO, 2016) aos olhos dos outros, algumas protetoras podem ver a si próprias como desajustadas até compreenderem que se trata de uma ação social, como indica Pinto (2016), e que, portanto, conformam um movimento social mais amplo.

Enfocando aspectos de gênero, é possível perceber um esvaziamento do protagonismo feminino pelo questionamento da racionalidade de suas agentes nessas ações e movimentos. Mas esse esvaziamento é também a reprodução de estereótipos característicos da sociedade ocidental moderna, que percebe nas mulheres uma tendência menor à racionalidade do que nos homens e, consequentemente, um risco perene de psicopatologias, já vistas como inatas ou como uma essência feminina.

Por que uma mulher seria considerada maluca por cuidar de animais de rua? O que incomoda outras pessoas para que critiquem uma forma de voluntariado baseado em compaixão e simetria moral? Em primeiro lugar, talvez toda mulher corra o risco de ser considerada maluca quando trata animais com atenção, respeito e cuidado, ou seja, a partir da ética do care, especialmente se ela se designa mãe desse animal. A maternagem interespecífica chama a atenção porque aciona representações de maternidade e feminilidade.

Gaard (s. d.) efetua uma crítica às formas pelas quais as mulheres são censuradas pelo cuidado que oferecem aos animais, sejam eles de companhia ou não. Numa visão machista, conforme elencada pela autora a partir de uma anedota,

[...] 1. o cuidado feminino dos animais deveria ser mais apropriadamente direcionado à prole biologicamente produzida de sua própria espécie, cujo pai é um homem; 2 . as mulheres podem ser 'curadas' do cuidado de outras espécies por meio da gestação; 3. e o cuidado feminino dos animais é uma variedade do instinto ou sentimento, portanto, de um valor menor do que as escolhas racionais masculinas no cuidado de animais (GAARD, s.d.).

Tanto a visão de que senhoras idosas seriam predominantes na proteção animal quanto a noção de que animais de estimação substituem filhos ${ }^{9}$ são criticadas como machistas e sexistas. O destino inevitável da maternidade é mobilizado como crítica. É nesse ponto que a autora se concentra. Sua visão da maternidade como uma escolha, e não um destino, permite sugerir que não apenas as mulheres podem escolher entre ser ou não mães, mas que podem escolher que tipo de filhos querem ter: naturais, adotados, da mesma raça/cor, ou de outras espécies. Ao assumir a maternagem humano-animal, contudo, a autora frisa que não se trata de comparar animais a crianças nem de reduzir toda a gama de ativismo animalitário aos processos de care. O cuidado dos animais, como tarefa militante de um ecofeminismo animalitário

[...] pode ser visto como um ato de desafio ao patriarcado, um passo fora das instituições que aprisionam nossas paixões e preocupações. O cuidado feminino dos animais é fundamentalmente, um ato feminista de resistência (GAARD, s. d.).

\footnotetext{
${ }^{9}$ Critiquei essa afirmação em Osório (2016a).
} 
A proposta é instigante na medida em que ela não submete os processos de maternagem a estereótipos sexistas, como se a sua recusa fosse um fundamento do feminismo e a sua adoção uma capitulação ao machismo. Ao mesmo tempo, a escolha pela maternagem intra ou interespecífica indica que, mesmo quando aparentemente seguindo scripts patriarcais, as mulheres podem estar dando passos para fora dos estereótipos de gênero. Abre-se um leque para compreender que há protagonismo feminino e uma crítica feminista implícita no movimento animalitário mesmo quando a atuação feminina é a da protetora que recolhe animais de rua e os leva para casa.

Não surpreende mais, portanto, que boa parte das protetoras que entrevistei afirmasse não ter filhos (biológicos). Longe de uma substituição de uma prole biológica por uma metafórica, é necessário indicar que a maternidade é uma opção em primeiro lugar. Assim, a mulher que opta por se declarar mãe de um animal individualizado pode ser vista, negativamente, como alguém que perdeu a conexão com seu destino biologicamente imaginado de parir e cuidar de crianças humanas. Essa desconexão, tida como psicopatológica pelo machismo (ou pelo patriarcado, conforme o tropo feminista), seria forte entre aquelas que sistematicamente recolhem animais nas ruas e os levam para suas casas, onde são medicados, cuidados e encaminhados para adoção, numa linguagem característica da vida familiar humana.

A leitura de Gaard (s.d.) segue a visão crítica da própria Gilligan quando, em uma entrevista concedida a duas autoras contemporâneas das teorias do care, Sandra Laugiere e Patrícia Paperman, faz uma distinção entre uma ética do care feminina e feminista. Segundo ela,

No universo genderizado do patriarcado, o care é uma ética feminina que reflete a dicotomia do gênero e a hierarquia do patriarcado. Cuidar dos outros é o que fazem as boas mulheres e as pessoas que cuidam (care) fazem um trabalho de mulheres. Elas são dedicadas aos outros, sensíveis às suas necessidades, atentas às suas vozes... E desaparecem (selfless) (GILLIGAN, 2009, p. 77).

Ao contrário, uma ética do care feminista, possível na democracia e em seu princípio de igualdade, conduz à libertação do patriarcado e suas outras formas de opressão, como o racismo, a homofobia e outras intolerâncias. Aqui, Gillingan aponta que o care não é uma questão de mulheres, mas uma preocupação humana: a moral que não oprime tampouco abandona. "Uma voz relacional que resiste às hierarquias patriarcais" (GILLIGAN, 2009 , p. 77) pode ser, também, uma voz que resiste às hierarquias interespecíficas, segundo às quais os humanos teriam prioridade nos cuidados e, sobretudo, nos cuidados advindos daquelas "boas mulheres". Ou, como coloca Molinier:

Se eu pensar nessa distinção à luz da minha pesquisa, uma ética feminina visaria satisfazer todo mundo e, principalmente, não atacar ninguém, acreditaria na possibilidade de aproximar a diretora e as cuidadoras e estaria pronta a empreender longos esforços para isso. Uma ética feminista, em compensação, tem consciência das rupturas e dos acordos. Ela não propõe uma conciliação, mas uma alternativa na qual não ganham todos. Ser feminista, nesse sentido, é não ceder (MOLINIER, 2014, p. 32).

O potencial crítico da proteção animalitária, na forma como o tenho pesquisado, transpassa os próprios papéis de gênero: cuidar não é um ato intrinsecamente ou essencialmente feminino, mas pode revelar novas possibilidades e potencialidades para mulheres e, antes de tudo, esse cuidado não cede. No caso das protetoras, não ceder à noção de que mulheres devem cuidar exclusivamente de humanos, ou que a maternagem não pode ser interespecífica, ou que os cuidados com os animais só podem ser posteriores 
aos cuidados com os humanos. Não ceder às visões sexistas que as rotulam como "malucas", que diminuem ou questionam suas ações protetivas e sua racionalidade. Não ceder ao care feminino, que subalterniza as mulheres, mas erguer uma "voz diferente", como indica Gilligan (1982), que também defende o bem-estar animal.

\section{Misantropia e misoteria}

A outra acusação caracteristicamente direcionada a esse universo, e que verifiquei muitas vezes enquanto fazia campo on-line, é a crítica ao cuidado dos animais em detrimento do humano. Como indica Luc Boltanski (1993), se há muitos desafortunados, a regra moral diz que é melhor ajudar a algum deles do que a nenhum. As protetoras que usualmente recebem esse tipo de crítica têm na manga uma resposta padronizada, uma acusação em forma de pergunta: e você, quem você ajuda? Aquele que critica o trabalho voluntário do outro, via de regra, não é voluntário em nada.

O que um questionamento como esse aponta, num primeiro plano, é para o desvalor moral e objetivo dos entes cuidados. Como objetos descartados numa sociedade de consumo de massa, cães e gatos de rua se tornam lixo. E mexer no lixo dos outros é ofensivo, sujo, poluidor e desrespeita aspectos da intimidade. Mas a origem dos animais de rua não é tão simples de desenhar quanto a noção de abandono, amplamente utilizada pela proteção animal, pode sugerir. Parte do abandono ocorre em locais onde se sabe que há protetores, em colônias, na porta de abrigos (MATOS, 2012) ou da casa dos protetores e mesmo em clínicas veterinárias. Esse hábito escamoteia o abandono como se a rua fosse um espaço de mediação entre um dono e outro. Ele não é propriamente deixado à deriva, jogado no lixo como um objeto, mas posto na porta de alguém como na imagem clichê do bebê recém-nascido numa cesta. Se bebês podem ser encaminhados ao poder público, os animais não. Assim, a pessoa que quer ou precisa se desfazer do animal, ainda que o ato seja malvisto pelas protetoras, e não encontra quem fique com ele, não tem a quem recorrer e resta apenas a rua como alternativa, subsumidas as opções acima elencadas. Não se trata sempre, portanto, de um objeto descartável, mas de um sujeito descartável. É claro que o descarte brutal também ocorre.

Posto isso, o estatuto do animal de rua pode nem sempre ser o de um objeto, mas não é muito melhor do que o estatuto de um morador de rua, exposto a toda sorte de violência, conjugada à indigência. Se há moradores de rua, crianças de rua e uma infinidade de outros desafortunados, por que cuidar de animais? Aqui, em geral, paira uma crítica misotérica aos protetores, que pode ser reforçada pela misantropia que eles mesmos muitas vezes abraçam, como observei on-line quando afirmam que "preferem bicho a gente". Misothery é o termo criado por Mason (1998) para definir atitudes e representações de ódio aos animais, seguindo as nuanças encontradas, por exemplo, na noção de misoginia, já indicando conexões ecofeministas no termo.

Se preferir animais pode ser misantrópico, ajudar animais não é, mas criticar aqueles que o fazem é misotérico, dado que refuta qualquer valor à vida do animal, delegando-o à plena objetificação de um ser imprestável. Essa objetificação do outro, seja ele racial, sexual ou etnicamente designada, é parte daquilo que permite uma visão ecofeminista que associa diversas formas de opressão a formas de dominação da natureza e dos animais. Adams (2007), nesse sentido, sublinha que esse tipo de pergunta feita constantemente às protetoras ${ }^{10}$ constrói uma hierarquia entre humanos e animais que constitui exatamente o

\footnotetext{
${ }^{10}$ Adams (2007) se pergunta como sensibilizar as pessoas para o sofrimento animal se elas são aparentemente insensíveis ao sofrimento humano, tomando como caso paradigmático os genocídios dos séculos XX e XXI, quando se dá conta de que a pergunta está equivocada.
}

14 Revista Estudos Feministas, Florianópolis, 26(3): e57762 
que permite o sofrimento animal, afastando a possibilidade de compaixão - o que ela chama de "uma economia conservadora da compaixão", como se essa fosse escassa no mercado e devesse ser bem aplicada" . Mas o cuidado, refuta, não funciona dessa forma, não se baseia em hierarquias entre merecedor/não merecedor.

A tensão entre misantropia e misoteria reatualiza a "grande divisão" natureza/cultura (LATOUR, 1994), além, é claro, de ser especista (SINGER, 2010) em ambos os lados e de revelar assimetrias múltiplas. Ou bem se ama os humanos, seres de cultura e valor moral, prioritários no cuidado, ou bem se ama os animais, que muitas protetoras veem como inocentes, vulneráveis e moralmente superiores aos humanos (OSÓRIO, 2016b). Há uma exclusão radical, para usar o termo de Gaard (2011a): as diferenças entre humanos e animais, e seu valor moral, são ampliadas a tal ponto que se deve escolher entre um e outro. Somem os pontos de conexão. É a posição, por exemplo, de Jean-Pierre Digard (2012), antropólogo francês dedicado à área de relações humano-animal que, paradoxalmente, criticou toda a gama de produção das ciências humanas e da filosofia animalitária que tentam empreender algum tipo de simetrização entre o humano e o animal. Para ele, a especificidade do humano desapareceu nessa abordagem, o que o leva a criticá-la como misantrópica.

Não posso dizer se a maioria das protetoras é ou não misantropa, mas apenas torço para que não seja e que a compaixão não se torne uma atitude escassa. Isso, contudo, não reduz nem desmerece o trabalho que exercem. Por outro lado, a misoteria ocidental contemporânea é parte de uma atitude de dominação da natureza que o ecofeminismo associa ao patriarcado e suas formas de opressão da mulher. É por misoteria que mulheres são associadas negativamente à natureza e aos animais. Assim, quando mulheres recusam o cuidado do humano (na recusa à reprodução, por exemplo) e se voltam ao cuidado dos animais e, mais ainda, quando sua visão destes (ainda que prioritariamente os de estimação) os associa a uma extrema vulnerabilidade, está-se diante de uma ética ecofeminista do care animalitário.

Adams, cujo pioneiro e emblemático The Sexual Politics of Meat ajudou a construir a conexão entre feminismo e vegetarianismo, resume em seu prefácio à edição de décimo aniversário:

E quando as pessoas me perturbam perguntando 'E os sem-teto, e as mulheres vítimas de violência?' e insistem que devemos ajudar os humanos em sofrimento primeiro, eu não me sinto descartada por uma assertiva tão estreita do campo do ativismo compassivo. E sei que vegetarianismo e ativismo animal em geral podem acompanhar o ativismo social em nome de pessoas privadas de direitos. E também sei que essa questão é, na verdade, uma resposta defensiva, uma tentativa de desviar da questão com a qual o interlocutor se sente desconfortável. É uma tentativa de ter superioridade moral. Apenas comedores de carne levantam essa questão. Nenhum defensor dos sem-teto que seja vegetariano, nenhum defensor de mulheres vítimas de violência que seja vegetariano jamais duvidaria que essas questões podem ser abordadas em conjunto. E mais, o ponto [crucial] de The Sexual Politics of Meat é que devemos parar de fragmentar o ativismo; nós não podemos polarizar os sofrimentos humano e animal porque eles estão interrelacionados (ADAMS, 2015, p. 15).

Exaustivamente, Adams (2015) demonstra a lógica de gênero por trás do atual consumo de carne, de modo que "os comedores de carne" aos quais se refere no trecho acima dialogam com um imaginário que associa animais a mulheres, e vice-versa, ambos

\footnotetext{
${ }^{11}$ Seguindo um paradigma utilitarista neoclássico de economia onde se visa o máximo lucro, ou seja, o lucro humano em detrimento do animal.
} 
objetos a serem explorados, tomados e oprimidos. Quando as protetoras que pesquiso se defrontam com perguntas semelhantes, não é apenas misoteria (MASON, 1998). Independente do sexo do interlocutor, há uma associação entre uma pretensa obrigação das mulheres de cuidar (care) preferencialmente dos humanos que está em jogo, obscurecendo as formas pelas quais a opressão de uns está relacionada às formas de opressão dos outros.

\section{O espaço privado do cuidado}

Por último, porém não menos importante, gostaria de chamar a atenção para a privatização do cuidado dos animais de rua, sua conexão com a ausência de políticas públicas de contenção dessa população e suas consequências para as mulheres. Curtin (1991) alerta que se a ética do care não for politizada, pode ser usada para privatizar os interesses morais das mulheres, que é basicamente o que ocorre no âmbito da proteção a animais de rua, um tipo de atividade primordialmente não remunerada, maciçamente feminina, dispendiosa e que privatiza um problema público, no sentido de que animais errantes e/ou colônias não são nem cuidadas nem propriamente geridas pelo estado, a não ser pelo extermínio, e são as mulheres que tomam para si, no âmbito mesmo de sua vida doméstica e privada, a tarefa de resgatar e/ou alimentar esses animais.

Politizar, no sentido empregado por Donovan (1996, p. 93), é "olhar para o contexto político e econômico no qual as pessoas devem fazer suas decisões morais", isto é, tomar sociologicamente o conjunto mais amplo de fatores que atuam sobre o cenário no qual se deve, individualmente, tomar decisões morais. E, em termos sociológicos mais amplos, se perguntar, em cada cenário, quem lucra com ele. Afinal, a "ética não se desenvolve num vácuo político" (DONOVAN, 1996, p. 95) e "a articulação das análises do cuidado em diferentes níveis não pode deixar de lado a ideia de responsabilidade, no mínimo para compreender como são distribuídas as responsabilidades de cuidado" (MOLINIER; PAPERMAN, 2015, p. 47).

No caso das protetoras, a lacuna de apoio estatal não afeta sua disposição para continuar cuidando de animais de rua, mas elas não desconhecem que o poder público tem uma parte a desempenhar nesse processo e que sua ausência torna a situação dos animais mais frágil e, consequentemente, a delas. Observe-se a fala de Daniela, entrevistada de 42 anos, que disponibilizei acima: "se tivesse em todos os municípios a questão da castração, não existiria tanto animal abandonado e não ia ter tanta gente, né, ocupando o tempo cuidando dos animais". Basicamente, o poder público que antes caçava cães de rua com a famigerada carrocinha, ao abandonar as práticas pregressas de extermínio, delegou à sociedade civil o cuidado dos animais de rua, um cuidado que o próprio estado, na verdade, nunca tomou para si.

A proteção a animais de rua não estabeleceu nenhum tipo de institucionalização real para além de uma ou outra experiência passageira em secretarias municipais de direitos dos animais, elas próprias intermitentes ${ }^{12}$. Ainda assim, tais experiências nunca chegaram a tornar tarefa do estado o interesse e/ou os cuidados dos animais de rua, delegando a proteção à sociedade civil, em especial à sua parcela feminina, conforme também observa Pinto (2016). Dentre alguns pleitos que pude observar nesse universo, a atuação estatal é sempre marcante, seja na forma de legislação que coíba o abandono de animais, tanto preventiva quanto punitiva, seja nas demandas constantes de hospitais

\footnotetext{
${ }^{12}$ Com o acirramento da retração econômica e o remodelamento do sistema de distribuição de renda pósPT, muitos dos novos prefeitos empossados em 2017 passaram a cortar tais secretarias no âmbito de uma contenção de gastos públicos.
}

16 Revista Estudos Feministas, Florianópolis, 26(3): e57762 
veterinários públicos e serviços correlatos (porém não exclusivos) a eles, como castrações, consultas e vacinações gratuitas. Independente de alguns municípios oferecerem parte desses serviços, atendimentos gratuitos são escassos, o que faz com que o trabalho das protetoras seja duplamente oneroso: tanto do ponto de vista financeiro quanto emocional.

O que me parece pertinente é que a ausência de mecanismos estatais de gestão de animais de rua fora dos procedimentos de extermínio abusa das práticas de care das protetoras, bem como a prática comum de se abandonar animais em suas portas, uma vez que as sobrecarrega. Essa sobrecarga se dá justamente porque o problema é extenso, difícil de gerir e solucionar a curto prazo e parece ter sido inteiramente privatizado ${ }^{13}$, onerando mais uma vez as mulheres. Essa privatização, de fato, é o que o torna praticamente insolúvel, já que entidades privadas não podem fazer o papel do estado, prevenindo e punindo formas de maus tratos aos animais.

Quando o estado se ausenta, delegando às mulheres uma ação que deveria ser sua, e muitas vezes criticando-as por essa ação, como no caso da gou mama (CHANG, 2012), estamos diante de um cenário típico de misoginia e estado patriarcal, para manter o tropo feminista. O trabalho gratuito das mulheres, sustentado pelas doações financeiras de suas redes de apoio mútuo, desonera economicamente o estado, privatizando e terceirizando sem controle uma ação que deveria ser também sua. Temos, então, majoritariamente mulheres se dedicando a cumprir tarefas que são de interesse público, competindo entre si por fontes de financiamento, financiando elas próprias suas ações e as de outras mulheres, enquanto o estado neoliberal capitalista opera no sentido de reduzir suas próprias ações a partir do paradigma do estado mínimo.

\section{Considerações finais}

É parte da tradição feminista tanto o debate acadêmico, inclusive entre suas correntes internas, quanto a militância política. Não afirmo que as protetoras de animais de rua brasileiras sejam ou não militantes feministas, ecofeministas ou tenham tido contato com as teorias do care. Não se trata de intelectualizar sua atuação, embora eu conheça protetoras que são intelectuais, acadêmicas e pós-graduadas. O objetivo do artigo foi um exercício analítico de aproximação entre o universo que pesquiso e o care animalitário, identificando pontos de confluência entre teorias feministas e práticas protetivas animalitárias.

De fato, Pinto (2016) já havia esboçado uma aproximação entre proteção e teorias do care, atenta à maioria feminina na proteção animal. Minha opção no presente trabalho foi radicalizar a proposta até o ecofeminismo. Creio que ainda há muito que este pode contribuir para análises sobre esse universo, visto que o feminismo tem inspirado reflexões tão distintas quanto a noção de misoteria (MASON, 1998) e de exploração animal (ADAMS, 2015). E se parte das críticas que as protetoras recebem também são direcionadas a outras mulheres, então uma leitura feminista parece pertinente para sublinhar que o viés de gênero traz consequências.

A frequente estereotipia do feminino como permeado por uma essência irracional, marcadamente emocional e mesmo insana não atinge, de certo, apenas as protetoras que pesquiso, mas são representações que perpassam discursos e práticas diversos. No âmbito do macromovimento animalitário, esse clichê parece ser acionado tanto de fora para dentro quanto entre correntes em disputa. Tomar algumas das críticas que as protetoras recebem por sua atuação voluntária foi um caminho para lançar luz sobre algumas das questões de gênero que perpassam o animalitarismo. Sem dúvida, existem outras.

\footnotetext{
${ }^{13}$ Discuti anteriormente como a legislação municipal carioca praticamente terceirizou o cuidado dos animais
} aos protetores (Osório, 2013). 


\section{Referências}

ADAMS, Carol J. "The war on compassion". In: DONOVAN, Josephine; ADAMS, Carol J. The feminist care tradition in animal ethics: a reader. New York: Columbia University Press, 2007. p. 21-38. 2015.

. The sexual politics of meat: A feminist-vegetarian critical theory. London: Bloomsbury,

ALBRIGHT, Katrina M. "The extensions of legal rights to animals under a caring ethic: an ecofeminist exploration of Steven Wise's Rattling the Cage". Natural Resources Journal, Albuquerque, v. 42, n. 4, p. 915-937, 2002.

BOLTANSKI, Luc. La souffrance a distance: morale humanitaire, médias et politique. Paris: Métailié, 1993.

BORGEAUD-GARCIANDÍA, Natacha. "Aproximaciones a las teorias del care. Debates passados. Propuestas recientes en torno al care como trabajo". Revista Latinoamericana de Estudios del Trabajo, Rio de Janeiro, ano 14, n. 22, p. 137-156, 2009.

CHANG, Chia-Ju. "Trans-species Care: Taiwan's Feral Dogs and Dog Mother Activism". International Journal of Humanities and Social Science, s/l, v. 2, n. 3, p. 287-294, 2012.

CURTIN, Deane. "Toward an ecological ethic of care". Hypatia, Hoboken, v. 6, n. 1, p. 60-74, 1991.

DELAPORTE, Yves. "Les chats du Père-Lachaise - contribution a l'ethnozoologie urbaine". Terrain - revue d'ethnologie de l'Europe, Paris, n. 10, p. 37-50, 1988.

DELEUZE, Gilles; GUATARRI, Félix. Mil platôs - capitalismo e esquizofrenia. v. 4. Rio de Janeiro: Editora 34, 1997.

DIGARD, Jean-Pierre. Le tournant obscurantiste en anthropologie: de la zoomanie à l'animalisme occidentaux. L'homme, Paris, n. 203-204, p. 555-578, 2012.

DONOVAN, Josephine. "Attention to suffering: a feminist caring ethic for the treatment of animals". Journal of Social Philosophy, v. 27, n. 1, p. 81-102, 1996.

"Feminism and the treatment of animals: from care to dialogue". Signs: Journal of Women in Culture and Society, Chicago, v. 31, n. 2, p. 305-329, 2006.

"Animal rights and feminist theory". In: DONOVAN, Josephine; ADAMS, Carol J. The feminist care tradition in animal ethics: a reader. New York: Columbia University Press, $p$. 58-86, 2007.

GAARD, Greta. Mothering, caring, and animal liberation. Disponível em http:// web.archive.org/web/20010524163525/http://www.farinc.org/newsletter/v8_n3-4_94/ mothering.html, s/d. Acesso em 16/03/2017.

"Rumo ao ecofeminismo queer". Revista Estudos Feministas, Florianópolis, v. 19, n. 01, p. 197-223, 2011 a.

"Ecofeminism revisited: rejecting essentialism and re-placing species in a material feminist environmentalism". Feminist Formations, Baltimore, v. 23, n.02, p. 26-53, 2011 b.

GAARDER, Emily. "Risk \& reward: The impact of animal rights activism on women". Society and Animals, Leiden, v. 16, n. 1, p. 1-22, 2008.

"Where the boys aren't: the predominance of women in animal rights activism". Feminist Formations, Baltimore, v. 23, n. 2, p. 54-76, 2011.

GILLIGAN, Carol. In a different voice. Cambridge: Harvard University Press, 1982.

"Le care, éthique feminine ou éthique féministe?" Multitudes, Paris, v. 37/38, n. 2/3, p.76-78, 2009.

GRUEN, Lori; BIRKE, Linda. “Ecofeminists' perspective”. In: BEKOFF, Marc (ed.). Encyclopedia of animal rights and animal welfare. Westport: Greenwood Press, p. 48-49, 1998.

HARAWAY, Donna J. When species meet. Minneapolis: University of Minnesota Press, 2008.

18 Revista Estudos Feministas, Florianópolis, 26(3): e57762 
KEAN, Hilda. Animal rights - political and social change in Britain since 1800. London: Reaktion, 1998.

LANSBURY, Coral. The old brown dog: women, workers, and vivisection in Edwardian England. Madison: University of Wisconsin Press, 1985.

LATOUR, Bruno. Jamais fomos modernos: ensaio de antropologia simétrica. Rio de Janeiro: Ed. 34. 1994.

A esperança de pandora: ensaios sobre a realidade dos estudos científicos. Bauru: EDUSC, 2001.

MASON, Jim. "Misothery". In: BEKOFF, Mark (ed.). Encyclopedia of animals rights and animal welfare. Westport: Greenwood Press, p. 245-246, 1998.

MATOS, Liziane Gonçalves de. Quando a "ajuda é animalitária" - um estudo antropológico sobre sensibilidades e moralidades envolvidas no cuidado e proteção de animais abandonados a partir de Porto Alegre/RS. 2012. Dissertação (Mestrado em Antropologia) - Programa de Pós-Graduação em Antropologia Social, Universidade Federal do Rio Grande do Sul, Porto Alegre, RS, Brasil.

MOLINIER, Pascale. El trabajo de cuidado e la subalternidad. Bogotá: Universidad Nacional de Colombia, 2012.

"Cuidado, interseccionalidade e feminismo". Tempo Social, São Paulo, v. 26, n. 1, p.17-33, 2014.

MOLINIER, Pascale; PAPERMAN, Patricia. "Descompartimentar a noção de cuidado?" Revista Brasileira de Ciência Política, Brasília, n. 18, p. 43-57, 2015

OSÓRIO, Andréa. "A cidade e os animais: da modernização à posse responsável". Teoria e Sociedade, Belo Horizonte, n. 21, v. 1, p. 143-176, 2013.

. "Mãe de gato? Reflexões sobre o parentesco entre humanos e animais de estimação". In: BEVILAQUA, Cimea; VANDER VELDEN, Felipe. Parentes, vítimas, sujeitos: perspectivas antropológicas sobre relações entre humanos e animais. Curitiba e São Carlos: Ed. UFPR, Ed.UFSCar, 2016a. p. 53-75.

. "Compaixão, moral e sofrimento animal entre protetores de gatos de rua". Iluminuras, Porto Alegre, v. 17, n. 42, p. 51-82, $2016 \mathrm{~b}$.

"Sociabilities and sensitivities: recruitments in homeless animal care". VIBRANT Virtual Brazilian Anthropology, Brasília, v. 13, n. 2, p. 143-159, $2016 \mathrm{c}$.

. "Dádiva e antiprofissionalização na proteção a animais de rua". Ambivalências, Aracajú, v.5 n. 10, p. 105-137, 2017.

PASTORI, Érica Onzi; MATOS, Liziane Gonçalvez de. 'Da paixão à 'ajuda animalitária': o paradoxo do 'amor incondicional' no cuidado e no abandono de animais de estimação". Caderno Eletrônico de Ciências Sociais, Vitória, v. 3, n. 1, p. 112-132, 2015.

PINTO, Leandra. Resgatando afetos: um estudo antropológico sobre redes urbanas de proteção animal. 2016. Dissertação (Mestrado em Antropologia) - Programa de PósGraduação em Antropologia Social, Universidade Federal do Rio Grande do Sul, Porto Alegre, RS, Brasil.

RAPCHAN, Eliane Sebeika; NEVES, Walter A. "Chipanzés não amam! Em defesa do significado", Revista de Antropologia, São Paulo, vol. 48, n. 2, p. 649-698, 2005.

REGAN, Tom. "A case for animal rights". In: FOX, M.W.; MICKLEY, L.D. (eds.). Advances in animal welfare science. Washington: The Humane Society of the United States, 1986. p. 179-189. The Thee Generation: reflections on the coming revolution. Philadelphia: Temple University Press, 1991. Jaulas vazias. Porto Alegre: Lugano, 2006.

SANTOS, Pedro da Silva. De Abandono, Proteção e Outras Formas de Relação com Animais: motivações, interações e diferenças no Rio de Janeiro e no sertão nordestino. 2014. 
Tese de Doutorado (Antropologia) - Programa de Pós-Graduação em Antropologia Social, Universidade Federal Fluminense, Niterói, RJ, Brasil.

SCHELER, Max. The Nature of Sympathy. Hamden: Archon, 1970.

SINGER, Peter. Libertação animal. São Paulo: Martins Fontes, 2010

WARREN, Karen J. "Ecological feminist philosophies: an overview of the issues". In:

(ed.). Ecological Feminist Philosophies. Indianapolis: Indiana University Press, 1996. p. ix-xxvi.

[Recebido em 17/06/2018 e

aceito em 05/10/2018]

Ecofeminism, Care Theory and the Criticism to Female Stray Animals Protectors

Abstract: The paper intends to analyze some of the criticism received bay female stray animals protectors, especially accusations of irrationality, misanthropy and sentimentalism. These accusations are read in the light of ecofeminism and care theory to perceive this kind of protection as an activity of care, mostly developed by women and subjected to sexist criticism. Ecofeminism is mobilized to combat the sexism in question, indicating the potential of animal protection to construct roles other than traditional roles for women.

Keywords: Stray animals protectors; Ecofeminism; Care theories; Misanthropy

Andréa Osório (andrea_osoriol@yahoo.com.br) é doutora em Antropologia pelo PPGSA/IFCS/UFRJ. Atualmente é professora adjunta na Universidade Federal Fluminense e professora permanente no Programa de Pós-Graduação em Ciências Sociais da Universidade Federal do Espírito Santo. Pesquisou relações de gênero em interseção com outros temas como religião (wicca), corpo (tatuagem) e educação. Sua pesquisa mais recente enfoca o protagonismo feminino em movimentos de proteção animal. Publicou diversos artigos em periódicos acadêmicos nacionais e capítulos de livros. 